\title{
EXÓTICAS INVASORAS NAS RODOVIAS BR 277, PR 508, PR 407, PARANÁ, BRASIL
}

\author{
Joema Carvalho ${ }^{1}$, Antonio Marcos Ferreira ${ }^{2}$, Mario Belão ${ }^{3}$, Roberto Boçon ${ }^{4}$ \\ ${ }^{1}$ Eng . Florestal, Doutoranda em Engenharia Florestal, UFPR, Curitiba, PR, Brasil - joemacarvalho@gmail.com \\ ${ }^{2}$ Geógrafo, Consultor Autônomo, Curitiba, PR, Brasil - amf.geo@gmail.com \\ ${ }^{3}$ Bacharel em Letras, Especialista em Meio Ambiente, Ecovia, Curitiba, PR, Brasil - mario.belao@ecovia.com.br \\ ${ }^{4}$ Biólogo, Dr., Mater Natura - Instituto de Estudos Ambientais, Araucária, PR, Brasil - rbocob@gmail.com
}

Recebido para publicação: 11/06/2013 - Aceito para publicação: 06/12/2013

\begin{abstract}
Resumo
Árvore exótica invasora é aquela que ocorre em uma área fora de seu limite natural e que se adapta e se reproduz, tornando-se dominante e alterando processos ecológicos naturais. As rodovias funcionam como um corredor de dispersão dessas espécies. Considerando isso, realizou-se um censo de todos os indivíduos de espécies arbóreas exóticas invasoras nas rodovias BR 277, PR 407 e PR 508, faixa de domínio da Concessionária Ecovia Caminhos do Mar S/A. As espécies foram definidas conforme a Portaria n 125/2009, do Instituto Ambiental do Paraná. Registraram-se 15 espécies e 3.939 indivíduos, sendo as principais: Pinus sp., Eucalyptus sp., Psidium guajava e Musa sp. Essas espécies localizam-se, principalmente, próximas a moradias. Verificou-se correlação entre as espécies e a altitude. Recomenda-se o manejo das mesmas, desenvolvimento de programas de conscientização ambiental, recuperação dos ambientes alterados através do plantio de espécies nativas e monitoramento para o controle dessas espécies.

Palavras-chave: Florística arbórea; altitude; biodiversidade.
\end{abstract}

\begin{abstract}
Exotic invasive trees on the road BR 277, PR 407 e PR 508, Paraná, Brazil. An exotic invasive species is one that occurs outside of its natural geographical limits, which adapts and reproduces, and becomes dominant and concessionaire conducted a survey of exotic invasive tree species. The highways serve as a traverse where exotic species are easily dispersed. An inventory of invasive exotic trees (Ordinance N ${ }^{\circ}$ 125/2009 of the Environmental Institute of Paraná) was carried out at the domain band of this concessionaire, on the highways BR 277, PR 407, and PR 508. 15 species were recorded as well as 3.939 individuals. The greatest instance species were: Pinus sp., Eucalyptus sp., Psidium guajava and Musa sp. These species are located primarily near the housing; there was a correlation between species and altitude. The management and tracking for the control of these species and environmental awareness programs are necessary, avoiding the planting of new subjects by de population and the dispersion in natural places, reestablishing the typical landscape of the present ecosystems on the road.

Keywords: Floristic; tree; altitude; biodiversity.
\end{abstract}

\section{INTRODUÇÃO}

Árvore exótica é aquela que ocorre em uma área fora de seu limite natural, resultante de dispersão por atividades humanas (INSTITUTO DE RECURSOS MUNDIAIS et al., 1992). Quando essas espécies se adaptam, se reproduzem e tornam-se dominantes, alterando processos ecológicos naturais, são consideradas invasoras (ZILLER, 2000).

As espécies invasoras são a segunda maior causa de extinção de espécies no planeta, afetando diretamente a biodiversidade, a economia e a saúde humana. A Convenção sobre a Diversidade Biológica (CDB) estabeleceu (Artigo 8) que os países signatários devem impedir a introdução e controlar ou erradicar espécies invasoras que ameaçam ecossistemas, hábitats e espécies nativas (MINISTÉRIO DO MEIO AMBIENTE E RECURSOS HÍDRICOS (MMA), 2006). Ao contrário de muitos problemas ambientais que se amenizam com o tempo, como a poluição química, as invasões biológicas se 
multiplicam, causando problemas que tendem a se agravar com o passar do tempo, impedindo que ecossistemas afetados se recuperem naturalmente (WESTBROOKS, 1998). Para o controle dos impactos causados por essas espécies, são necessários a retirada, o monitoramento e o controle (INSTITUTO AMBIENTAL DO PARANÁ (IAP), 2006).

As translocações de espécies aconteceram com objetivo econômico, para suprir necessidades agrícolas, florestais e ornamentais, e pelo desejo de imigrantes de recriar a paisagem de suas terras de origem (WELLS et al., 1986; RICHARDSON; HIGGINS, 1998; BINGGELI, 2000). As rodovias funcionam como um corredor onde as invasoras são disseminadas abundantemente. As sementes dessas espécies são transportadas através dos veículos, dos ventos e da turbulência gerada, favorecendo a dispersão (FORMAN et al., 2003). A invasão biológica por exóticas invasoras gera perda da biodiversidade nativa, por comprometer a estrutura, a composição florística e as dinâmicas de ecossistemas naturais, sendo uma das consequências da homogeneização de ambientes naturais. Esse fato refere-se ao aumento na similaridade de espécies no espaço ao longo do tempo, podendo ocorrer através de vários mecanismos ecológicos, um dos quais a substituição de espécies nativas (extinções) por exóticas, como consequência das alterações antrópicas no meio ambiente (OLDEN, 2006; OLDEN; POFF, 2004).

É um processo contínuo, em que uma região torna-se, cada vez mais, diferente da sua composição biológica original. Ocorre redução do número de espécies, depreciação genética dentro da espécie e simplificação do ecossistema, considerando a dinâmica ou interação dos fatores bióticos e abióticos. É considerada uma das principais formas do empobrecimento do ambiente natural (OLDEN et al., 2004). Também contribui para a perda da identidade da paisagem regional, que se torna cada vez mais homogênea (McKINNEY, 2006).

A faixa de domínio da Ecovia Caminho do Mar percorre trechos na área de abrangência da Floresta Ombrófila Mista e da Floresta Ombrófila Densa e ecossistemas como as Formações Pioneiras de Influência Aluvial e Marinha, constituintes do Bioma Mata Atlântica (INSTITUTO BRASILEIRO DE GEOGRAFIA E ESTATÍSTICA (IBGE), 2012). No estado do Paraná, esse bioma ocupava uma área de 19.639.352 ha e, com base em dados de 2012, 2.324.370 ha (11,8\% do total) (FUNDAÇÃO SOS MATA ATLÂNTICA; INSTITUTO NACIONAL DE PESQUISAS ESPACIAIS (INPE), 2013). Verificam-se áreas consideradas como Zona Tampão ou que transpõem Unidades de Conservação, como o Parque Nacional Saint Hilaire-Lange, o Parque Estadual do Pau Oco, a Floresta Estadual do Palmito, a APA da Serra do Mar, a APA Estadual do Rio Pequeno e a APA Estadual de Guaratuba, responsáveis pela preservação ou conservação de biomas e/ou ecossistemas da região, o que reforça a necessidade do controle das espécies exóticas invasoras.

Diante desse contexto, realizou-se o levantamento das espécies exóticas invasoras arbóreas e bananeiras, nas rodovias BR 277, PR 407 e PR 508, na faixa de domínio da Concessionária Ecovia Caminho do Mar S/A. O estudo foi desenvolvido para a obtenção de informações para a realização do Plano de Manejo e Controle dessas espécies. Especificamente, buscou-se responder às seguintes questões: Quais espécies exóticas invasoras ocorrem nessas rodovias? Há correlação entre a espécie e a densidade de indivíduos exóticos com a altitude? As espécies exóticas neste estudo amostradas apresentam sensibilidades distintas em função do acréscimo da altitude?

\section{MATERIAL E MÉTODOS}

A faixa de domínio da Ecovia Caminhos do Mar situa-se na área de abrangência das tipologias Floresta Ombrófila Mista e Floresta Ombrófila Densa, integrantes do Bioma Mata Atlântica. Encontramse as Formações Pioneiras de Influência Flúvio-Lacustre, formações associadas a esses biomas, como os branquilhais em Curitiba e Região Metropolitana, e os caxetais no litoral (IBGE, 2012) (Figura 1).

Conforme Köppen, o clima varia de Af - clima tropical superúmido sem ocorrência de geada, com médias anuais de temperatura do mês mais quente de $25{ }^{\circ} \mathrm{C}$ e do mês mais frio inferior a $17{ }^{\circ} \mathrm{C}$ (litoral e sopé oriental da Serra do Mar) - a Cfb - clima subtropical úmido (mesotérmico), sem estação seca, verão brando e geadas severas e frequentes, com médias anuais de temperatura do mês mais quente inferior a $22{ }^{\circ} \mathrm{C}$ e do mês mais frio inferior a $18{ }^{\circ} \mathrm{C}$ (Curitiba e Região Metropolitana) (INSTITUTO AGRONÔMICO DO PARANÁ (IAPAR), 1978). 
A altitude encontra-se próxima ao nível médio do mar, no litoral, chegando a 945 m.s.n.m., em Curitiba, Primeiro Planalto Paranaense.

As rodovias BR 277, PR 407 e PR 508, faixa de domínio da Concessionária Ecovia Caminho do Mar S/A, possuem, respectivamente, $84,2 \mathrm{~km}, 19 \mathrm{~km}$ e $32 \mathrm{~km}$ de comprimento. Para o cálculo da área de amostragem, estimou-se a faixa de domínio, desconsiderando a pista e área de segurança.

Realizou-se um censo de todos os indivíduos arbóreos de espécies exóticas invasoras situados nessa área, que foram amostrados e quantificados. Através desse levantamento, identificaram-se essas espécies e obteve-se o número de indivíduos e as frequências das mesmas.

Realizou-se o trabalho em 2008, portanto, considerou-se espécie exótica invasora conforme a Portaria do Instituto Ambiental do Paraná (IAP) nº 95/1997, atualmente substituída pela Portaria $n^{\circ} 125 / 2009$. Dessa forma, incluiu-se Eucalyptus sp. na amostragem, pois é considerada invasora conforme a Portaria n 95/1997.

As bananeiras foram consideradas como agrupamentos e classificados em pequenos (p), médios (m) e grandes (g). Para os cálculos, foram atribuídos pesos de 1 a 3 , respectivamente. Realizou-se a pontuação de forma qualitativa, baseada na percepção visual. As frequências foram calculadas considerando o tamanho e as rodovias.

Cada espécie ou povoamento amostrado, através da quilometragem e estaca (numeração realizada pela concessionária e alocada a cada $20 \mathrm{~km}$ ) da rodovia, foi georreferenciado. Posteriormente, os dados alfanuméricos foram lançados em um banco de dados associados à informação espacial em um Sistema de Informações Geográficas (SIG), para elaboração de um mapa. A partir desse sistema, as informações existentes no banco de dados sobre árvores exóticas e invasoras foram recuperadas a partir de sua localização agrupada por quilômetro.

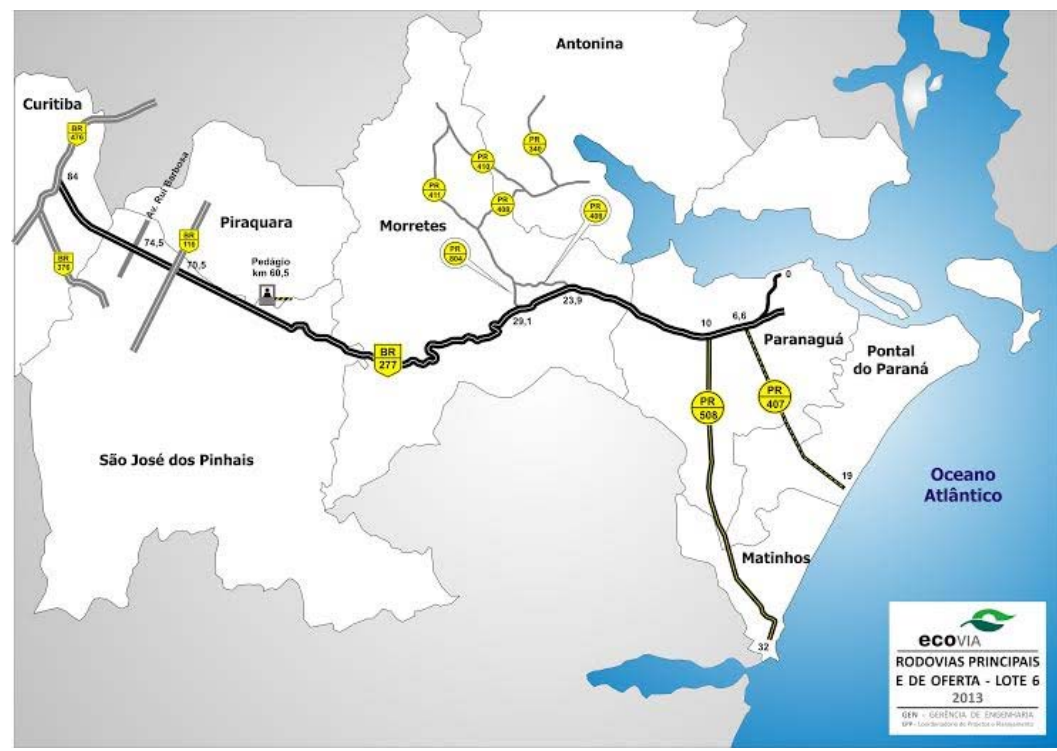

Figura 1. Localização das rodovias BR 277, PR 407 e PR 508.

Figure 1. Localization of roads BR 277, PR 407 and PR 508.

Para responder as perguntas discriminadas na introdução, realizou-se uma análise de ordenação, denominada Análise de Coordenadas Principais (PCoA) (GOWER, 1966). Esse tipo de ordenação é similar à análise de componentes principais, no entanto, difere da dela, principalmente, devido ao tipo de distância utilizada. A análise de componentes principais se restringe a utilizar a distância euclidiana, que é muito sensível a distribuições fuzzi de dados. A ordenação foi utilizada para verificar se existe relação entre a altitude e a densidade de indivíduos exóticos, respondendo, assim, uma das hipóteses do estudo. Os agrupamentos das espécies em função da altitude também foram visualizados mediante a PCoA, neste contexto. A distância utilizada foi Sorensen, e o número de coordenadas principais foi determinado pelo teste de randomização com 999 permutações. As análises foram efetuadas com o auxílio do programa PCORD 6.0 (MCCUNE; MEFFORD, 2011). Realizou-se essa análise na rodovia BR 277, pois foi a única que apresentou gradiente altitudinal. 


\section{RESULTADOS}

Observaram-se 15 espécies e 3.939 indivíduos arbóreos, seis espécies foram exclusivas na BR 277 e uma na PR 407. Apenas a Spathodea campanulata não foi verificada na BR 277 (Tabela 1).

O maior número de indivíduos foi verificado na BR 277, devido a sua maior extensão (84 km), seguida pela PR 508 (29 km) e PR 407 (19 km). A espécie com o maior número de indivíduos na BR 277 e na PR 407 foi Psidium guajava, e na PR 508 Eucalyptus sp. A incidência de Pinus sp. foi maior na BR 277 (Tabela 1). No caso da BR 277, o maior número de indivíduos ocorreu no início da rodovia, nas altitudes mais baixas da planície litorânea. Na região central dessa rodovia, que é a Serra do Mar, verificaram-se os povoamentos comerciais de Pinus sp., onde observa-se concentração dessa espécie (Figura 2).

Tabela 1. Número total de espécies e número de indivíduos total por espécie, nas rodovias amostradas. Table 1. Total number of species and number of individual total per species, sampled on the road.

\begin{tabular}{lccccccc}
\hline \multirow{2}{*}{ Nome Científico } & \multicolumn{2}{c}{ BR 277} & \multicolumn{2}{c}{ PR 407 } & \multicolumn{2}{c}{ PR 508 } & \multirow{2}{*}{ Total } \\
\cline { 2 - 7 } & N. Ind. & FR (\%) & N. Ind. & FR (\%) & N. Ind. & FR (\%) & \\
\hline Psidium guajava L. & 1.301 & 27,6 & 230 & 27,8 & 215 & 41,4 & 1.746 \\
Pinus sp. & 1.106 & 23,0 & 60 & 22,2 & 42 & 19 & 1.208 \\
Eucalyptus sp. & 294 & 9,2 & 6 & 3,7 & 227 & 13,8 & 527 \\
Syzygium cumini L. (Skeels) & 85 & 5,3 & 48 & 14,8 & 19 & 12,1 & 152 \\
Ligustrum lucidum W. T. Aiton. & 74 & 5,3 & & & & & 74 \\
Terminalia cattapa L. & 68 & 4,6 & 36 & 14,8 & 7 & 3,4 & 111 \\
Morus nigra L. & 21 & 7,2 & & & & & 21 \\
Leucaena leucocephala (Lam.) de Wit & 21 & 2,6 & & & 1 & 1,7 & 22 \\
Melia azedarach L. & 19 & 4,6 & 2 & 1,9 & & & 21 \\
Hovenia dulcis Thunb. & 14 & 2,0 & & & & & 14 \\
Citrus limon (L.) Burm. f. & 12 & 3,3 & & & & & 12 \\
Eriobotrya japonica (Thunb.) Lindl & 11 & 4,6 & 2 & 3,7 & 1 & 8,6 & 14 \\
Pittosporum undulatum Vent. & 2 & 0,7 & & & & & 2 \\
Spathodea campanulata P. Beauv. & & & 15 & 11,1 & & & 15 \\
\hline Total & 3.028 & 100,0 & 399 & 100,0 & 512 & 100,0 & 3.939 \\
\hline
\end{tabular}

N. Ind.: número de indivíduos; FR: frequência relativa.

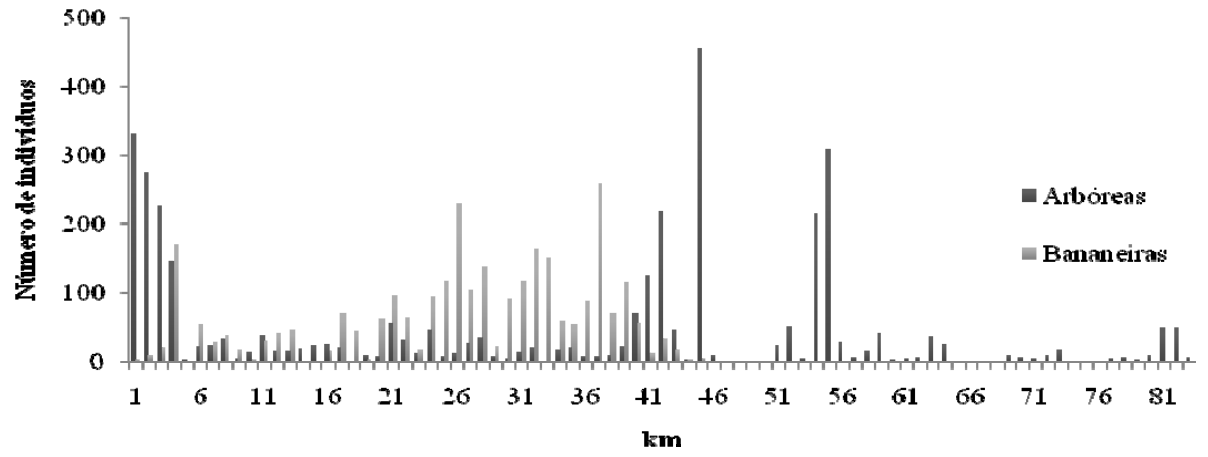

Figura 2. Arbóreas e bananeiras por km nas margens da BR 277.

Figure 2. Trees and banana trees per $\mathrm{km}$ in the BR 277.

Psidium guajava possuiu a maior frequência relativa nas três rodovias, destacando-se principalmente na PR 508. Pinus sp. foi a segunda espécie que se destacou nesse parâmetro. Syzygium cumini e Terminalia cattapa foram bastante expressivas na PR 407.

O maior número de aglomerados de Musa sp. foi registrado na BR 277, devido a sua extensão em proporção às demais rodovias, seguida pela PR 508 e PR 407. Observou-se que os aglomerados de bananeiras ocorreram na planície litorânea e na Serra do Mar da BR 277. Nas demais rodovias, os aglomerados de Musa sp. encontram-se distribuídos ao longo de seu percurso (Figura 2; Tabela 2). 
A frequência do tamanho dos aglomerados de bananeiras foi similar na BR 277. Porém o peso maior foi para aglomerados grandes. Considerando a PR 407, os aglomerados pequenos foram superiores aos menores e observou-se ausência de aglomerados grandes. Em relação à PR 508, a frequência foi superior para aglomerados pequenos, porém o peso foi maior para aglomerados médios (Tabela 2).

Tabela 2. Tamanho, frequência e pesos de aglomerados de Musa sp.

Table 2. Size, frequency and weight of clusters of Musa sp.

\begin{tabular}{lcccccc}
\hline \multirow{2}{*}{ Tamanho } & \multicolumn{2}{c}{ BR 277 } & \multicolumn{2}{c}{ PR 407 } & \multicolumn{2}{c}{ PR 508 } \\
\cline { 2 - 7 } & FR (\%) & Pesos & FR (\%) & Pesos & FR (\%) & Pesos \\
\hline Pequeno & 37,7 & 105 & 80,0 & 31 & 57,6 & 64 \\
Médio & 35,3 & 552 & 20,0 & 16 & 30,3 & 105 \\
Grande & 27,0 & 1.753 & 0,0 & & 12,1 & 93 \\
\hline Total & 100,0 & 2.410 & 100,0 & 47 & 100,0 & 262 \\
\hline
\end{tabular}

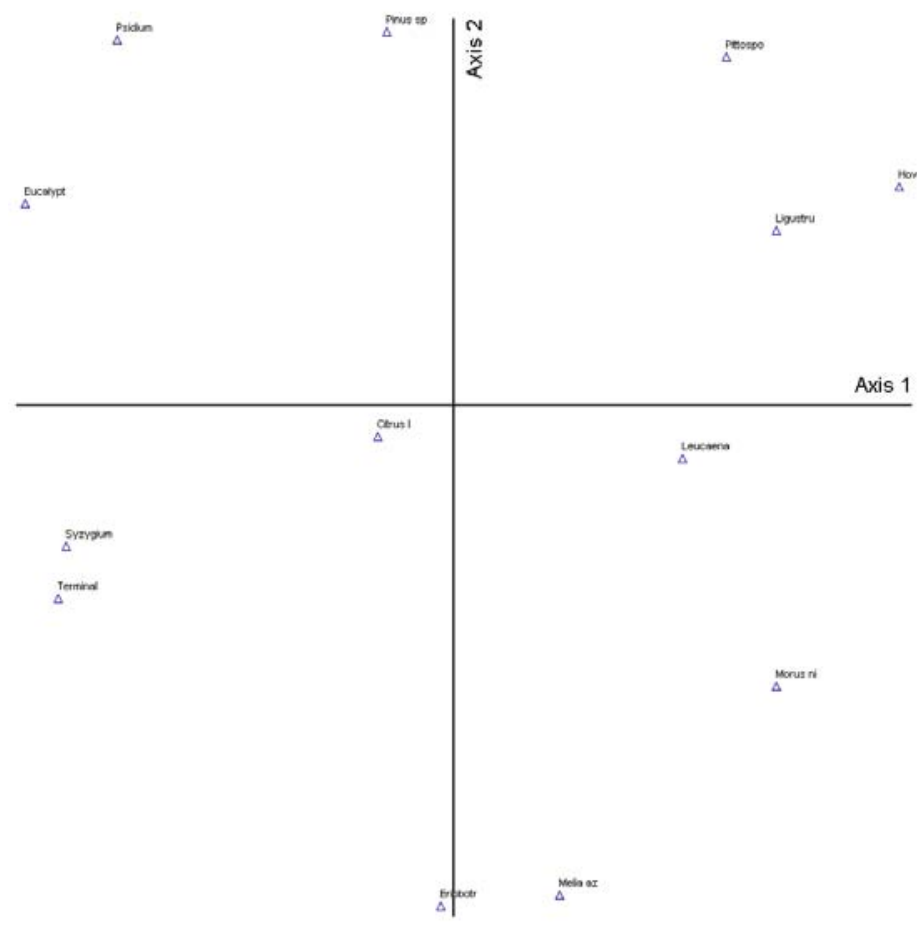

Figura 3. Correlação entre distribuição das espécies exóticas invasoras e altitude, rodovia BR 277, Paraná.

Figure 3. Correlation between the distribution of invasive alien species and altitude, road BR 277, Paraná State.

\section{DISCUSSÃO}

Muitas espécies exóticas invasoras foram introduzidas no Brasil desde períodos coloniais e, como consequência, foram incorporadas à cultura regional, como é o caso dos aglomerados de Musa spp. presentes nas regiões litorâneas (BISPO, 2009; LORENZI et al., 2006). Essa espécie adaptou-se devido às condições ambientais favoráveis (CORDEIRO, 2003). Psidium guajava é encontrada em pomares caseiros e em cultivos comerciais (LORENZI et al., 2006). Alguns autores consideram a espécie como nativa (LORENZI et al., 2006) e outros como exótica, considerando a espécie nativa da América Central (BLUM et al., 2008). Para os ecossistemas litorâneos, a espécie é invasora e compete com as espécies nativas, comprometendo a estrutura e a composição originais. Esse comportamento agressivo da espécie não foi verificado na região de Curitiba, possivelmente por ser uma espécie de origem tropical e subtropical, não tolerante ao frio (SOUZA et al., 2009) (Figura 2). 
Os gêneros Pinus e Eucalyptus foram significativos na amostragem, considerando-se o número de indivíduos e a frequência dessas espécies. Constatou-se que os plantios observados são comerciais, vinculados a empresas ou como complemento de renda dentro da propriedade rural. Com o advento da lei de incentivos fiscais (Lei $n^{\circ}$ 5.106/1966), vigente no Brasil no período 1966-1987, que beneficiou indústrias de base florestal que investiam em plantios florestais, desencadeou-se um intenso processo envolvendo plantações florestais principalmente com essências exóticas, como Pinus sp. e Eucalyptus sp. (ROSOT et al., 2004) (Figura 2).

Esses gêneros são os mais utilizados mundialmente para plantios comerciais. São tolerantes a diferentes condições pedológicas e climáticas, com boa margem para melhoria de produtividade através da adoção de práticas silviculturais básicas. Apresentam crescimento rápido e disponibilidade de sementes, em geral oriundas de seleção e melhoramento genético, enquanto que sementes de espécies nativas dificilmente estão disponíveis no mercado (RICHARDSON, 1999). Os países tropicais têm deficiências no conhecimento referente a silvicultura e a autoecologia de espécies nativas, sendo este um dos principais motivos que os levam a adotar espécies exóticas, pelo fato de possuírem informações abundantes sobre essas questões (ZILLER, 2000). Conforme o estudo, observou-se que o gênero Pinus tem maior ocorrência em altitudes superiores, ao contrário do Eucalyptus (Figura 2).

Os povoamentos de espécies exóticas invasoras fora da faixa de domínio não foram incluídos no trabalho, porém observa-se que eles causam impactos ambientais, devido ao seu potencial de disseminação. Por possuírem sementes aladas, dispersas pelo vento, a disseminação dessas espécies atinge grandes extensões (LORENZI et al., 2003). Um dos problemas mais graves do hemisfério Sul, relacionado à contaminação biológica, diz respeito à invasão de ecossistemas nativos pelo gênero Pinus. Essas contaminações são resultado da adoção de práticas de produção florestal que negligenciam o entendimento dos princípios que influenciam a migração e a dispersão de espécies em diferentes escalas espaciais (GARCÍA-MOZO et al., 2004).

Observou-se que a frequência de Syzygium cumini foi significativa na PR 407 e PR 508, na planície litorânea. Essa espécie é originária da Indonésia, da China e das Antilhas. É uma planta de grande porte que se adaptou muito bem às condições brasileiras. Pode ser encontrada em grande parte do Brasil, nas planícies litorâneas, nas serras e nos planaltos, e cresce muito bem em vários tipos de solo (GOMES, 1983). Outra espécie que também foi significativa na amostragem foi Terminalia cattapa. Originária da Ásia e Madagascar (LORENZI, 2003), espalhou-se pela costa brasileira, sendo utilizada no paisagismo urbano, devido a sua característica perene (SANCHES, 2009).

As demais espécies arbóreas foram encontradas nas áreas urbanas e/ou associadas a moradias esporádicas ao longo das rodovias, ocorrendo em menor quantidade na amostragem total. São utilizadas em arborização, paisagismo ou pomares, como Ligustrum lucidum, Terminalia cattapa, Leucaena leucocephala, Melia azedarach, Pittosporum undulatum, Spathodea campanulata, Hovenia dulcis, Syzygium cumini, Morus nigra, Citrus limon e Eryobotrya japonica (BLUM et al., 2008; LORENZI et al., 2003) (Figura 2).

Hovenia dulcis, Morus nigra, Citrus limon e Eryobotrya japonica são frutíferas, consumidas e cultivadas pela população. Morus nigra é utilizada para a produção de geleias e suas folhas são alimentos para o bicho-da-seda em explorações comerciais (LORENZI et al., 2003). Citrus limon, também, é cultivado em pomares caseiros e comerciais (LORENZI et al., 2006). Essas espécies, junto a Ligustrum lucidum, Melia azedarach, Pittosporum undulatum e Psidium guajava, possuem dispersão zoocórica. Desse modo, sua disseminação é potencializada, conforme observado em um trabalho desenvolvido no Parque Estadual Lago Azul, em Campo Mourão, Paraná (VIGILATO; ZAMPAR, 2011).

Conforme a Análise dos Componentes Principais (PCoA), considerando os dois eixos, a variância foi de 36,24\%. As espécies foram agrupadas nos quatro quadrantes com base na densidade e altitude de ocorrência. As espécies que ocorreram nas altitudes mais baixas foram agrupadas nos quadrantes da esquerda, e as espécies de ocorrência nas altitudes superiores, nos quadrantes da direta. As três espécies de maior ocorrência na amostragem foram agrupadas no mesmo quadrante. Eucalyptus sp. e Psidium guajava encontram-se em altitudes mais baixas e, na distribuição estatística, encontram-se mais próximas de Pinus sp., que ocorreu em altitude mediana na Serra do Mar, portanto, mais próximo do eixo y. Na região Metropolitana de Curitiba, local de maior altitude, a densidade foi inferior, por coincidir com área urbana. A maior parte das espécies exóticas invasoras localizadas nessa situação encontra-se na arborização urbana dos municípios da Região Metropolitana de Curitiba (Figura 2). 
Observaram-se aglomerados de Musa sp. nas margens de corpos d'água e em encostas, de maneira dominante, comprometendo totalmente o desenvolvimento da estrutura e a composição florística da vegetação nativa. Por terem raízes superficiais, esses locais ficam desprotegidos e suscetíveis à ocorrência de erosão, comprometendo a qualidade do corpo d'água e a estrutura da encosta em questão. Conforme a Lei 12.651/2012, que instituiu o Novo Código Florestal Brasileiro, essas áreas são legalmente protegidas e devem ser preservadas ou recuperadas com vegetação nativa.

Por meio das informações obtidas, elaborou-se um programa de manejo das Arbóreas Exóticas Invasoras. Como prioridade de manejo, são consideradas as Áreas de Preservação Permanente (APP) e os pontos que apresentaram maior número de ocorrências de espécies exóticas invasoras. A forma mais indicada para o controle de algumas espécies é a remoção imediata, como é o caso do Pinus sp., conforme realizado na Estação Ecológica de Itirapina, SP (ZANCHETTA; PINHEIRO, 2007).

\section{CONCLUSÃO}

- Em trechos onde a ocupação humana é marcante, verificam-se concentrações maiores de exóticas invasoras e também em locais com plantios comerciais. Observa-se, portanto, uma paisagem homogênea que contrasta com a paisagem natural típica da região.

- $\quad$ O trecho da BR 277 que liga o município de Curitiba e sua região metropolitana ao litoral do estado do Paraná trata-se de um transecto entre a Floresta Ombrófila Mista e a Floresta Ombrófila Densa, integradas ao Bioma Mata Atlântica. Dessa forma, através desse trabalho foi possível observar a preferência de ambientes com base no gradiente altitudinal pelas exóticas invasoras.

- Diante de um contexto de homogeneização das áreas naturais, decorrente da interferência antrópica e alteração de ambientes naturais, verifica-se perda da biodiversidade, com possível extinção de espécies nativas e crescente ocupação de espécies exóticas invasoras, substituindo as nativas e descaracterizando a paisagem local. Sendo assim, as exóticas invasoras, por terem se tornado abundantes, acabam sendo indicadoras de altitude e clima, como Pinus spp., Psidium guajava e Musa spp.

- $\quad$ Psidium guajava, Hovenia dulcis, Syzygium cumini, Eryobotrya japonica, Morus nigra, Citrus limon, Ligustrum lucidum, Melia azedarach e Pittosporum undulatum estão inseridas na cultura e economia regionais, fazendo parte da renda de pequenos proprietários rurais, da arborização urbana e de paisagismo.

- $\quad$ O controle dessas espécies deve envolver a educação ambiental visando à conscientização e à orientação referente ao local, forma de plantio e controle da dispersão. É necessário o fomento de pesquisa com o objetivo de desenvolver uma base adequada de conhecimentos referente ao comportamento das espécies exóticas invasoras. O monitoramento também é uma ação fundamental para a detecção precoce de novos indivíduos invasores, sendo, portanto, base para o controle dessas espécies. Além disso, é preciso adotar políticas que viabilizem a retirada dessas espécies e incentivem a substituição delas por nativas da região, conforme exemplos já observados no município de Curitiba, estado do Paraná, e outras localidades no Brasil.

\section{AGRADECIMENTO}

À Ecovia Caminho do Mar Ltda., ao Dr. Franklin Galvão e à Dra. Kelly Geronazzo Martins.

\section{REFERÊNCIAS}

BINGGELI, P. The human dimensions of invasive human plants. 2001. Disponível em: <http: www.members.tripod.co.uk/WoodyPlantEcology>. Acesso em: 09/02/2009.

BISPO, A. A. Musa sapientium: da banana na história cultural e da banana como alegoria. Revista Brasil-Europa: Correspondência Euro-Brasileira, Gummersbach, v. 118/10, n. 2, 2009.

BLUM, C. T.; BORGO, M.; SAMPAIO, A. C. F. Espécies exóticas invasoras na arborização de vias públicas de Maringá, PR. Revista da Sociedade Brasileira de Arborização Urbana, Piracicaba, v. 3, n. 2, p. $78-97,2008$. 
BRASIL. Lei n. 5.106, de dois de setembro de 1.966. Dispõe sobre os incentivos fiscais concedidos a empreendimentos florestais. Diário Oficial da União, Brasília, DF, dois de set. 1966. Disponível em <http://www.planalto.gov.br/ccivil_03/leis/1950-1969/L5106.htm>. Acesso em: 02/08/2013.

BRASIL. Lei n. 12.651, de 25 de maio de 2.012. Dispõe sobre a proteção da vegetação nativa; altera as Leis $\mathrm{n}^{\text {os }}$ 6.938, de 31 de agosto de 1981, 9.393, de 19 de dezembro de 1996, e 11.428, de 22 de dezembro de 2006; revoga as Leis nos 4.771, de 15 de setembro de 1965, e 7.754, de 14 de abril de 1989, e a Medida Provisória $\mathrm{n}^{\circ}$ 2.166-67, de 24 de agosto de 2001; e dá outras providências. Diário Oficial da União, Brasília, DF, vinte e cinco de maio de 2012. Disponível em <http://www.planalto.gov.br/ccivil_ 03/_Ato2011-2014/2012/Lei/L12651.htm>.

CORDEIRO, Z. J. M. Cultivo da banana para o estado de Rondônia. Embrapa Mandioca e Fruticultura Sistema de Produção, v. 1, Rio de Janeiro, 2003, versão eletrônica. <http://sistemasdeproducao.cnptia. embrapa.br/FontesHTML/Banana/BananaRondonia/clima.htm\#topo>. Acesso em: 09/02/2009.

FORMAN, R. T. T.; SPERLING, D.; BISSONETTE, J. A.; CLEVENGER, A. P.; CUTSHALL, C. D.; DALE, V. H.; FAHRIG, L.; FRANCE, R.; GOLDMAN, C. R.; HEANUE, K.; JONES, J. A.; SWANSON, F. J.; TURRENTINE, T.; WINTER, T. C. Road Ecology: Science and solutions. Island Press: Washington D. C, 2003. 482 p.

GARCÍA-MOZO, H.; COMTOIS, P.; KUEHNE, E. Aerobiological clines: The role of topography as a barrier for establishing dispersal corridors. Aerobiologia, New York, v. 20, n. 2, p. 161 - 172, 2004. Disponível em: http://www.springerlink.com/content/x271w73366v04 u64/. Acesso em: 09/02/2009.

GOMES, R. P. Fruticultura brasileira. 9. ed. São Paulo: Nobel, 1983. 446 p.

GOWER, J. C. Some distance properties of latent root and vector methods used in multivariate analysis. Biometrika, Oxford, v. 53, p. 325 - 338, 1966.

INSTITUTO AGRONÔMICO DO PARANÁ (IAPAR). Cartas climáticas básicas do estado do Paraná. Londrina: IAPAR, 1978. 41 p.

INSTITUTO AMBIENTAL DO PARANÁ (IAP). Unidades de Conservação: Ações para a Valorização da Biodiversidade. Curitiba: IAP, 2006. 344 p.

Portaria IAP no 95, de 22 de maio de 2.007. <http://www.iap.pr.gov.br/modules/conteudo/ conteudo.php?conteudo=812>. Acesso: 09/12/2008.

Portaria $\mathbf{n}^{\circ}$ 125, de 7 de agosto de 2.009. <http://www.iap.pr.gov.br/modules /conteudo/conteudo.php?conteudo=812>. Acesso em: 11/11/2013.

INSTITUTO BRASILEIRO DE GEOGRAFIA E ESTATÍSTICA (IBGE). Manual Técnico da Vegetação Brasileira. 2. ed. Série Manuais Técnicos em Geociências, n 1. Rio de Janeiro: IBGE, 2012. 271 p. Disponível em <ftp://geoftp.ibge.gov.br/documentos/recursos_naturais/manuais_tecnicos/manual_ tecnico_vegetacao_brasileira.pdf>.Acesso em: 12/11/2013.

INSTITUTO DE RECURSOS MUNDIAIS; UNIÃO MUNDIAL PARA A NATUREZA; PROGRAMA DAS NAÇÕES UNIDAS PARA O MEIO AMBIENTE. A estratégia global para a biodiversidade diretrizes de ação para estudar, salvar e usar de maneira sustentável e justa a riqueza biota da Terra. Curitiba: World Resources Institute e Fundação O Boticário de Proteção à Natureza, 1992. 232 p.

LORENZI, H.; SOUZA, H. M.; TORRES, M. A. V.; BACHER, L. B. Árvores exóticas no Brasil: madeireiras, ornamentais e aromáticas. Nova Odessa: Instituto Plantarum, 2003. 384 p.

LORENZI, H.; BACHER, L. B.; LACERDA, M.; SARTORI, S. Frutas brasileiras e exóticas cultivadas no Brasil. Nova Odessa: Instituto Plantarum, 2006. 672 p.

McCUNE, B.; MEFFORD, M. J. PC-ORD: Multivariate Analysis of Ecological Data. Version 6.0MjM Software. Gleneden Beach, 2011. 
McKINNEY, M. L. Urbanization as a major cause of biotic homogenization. Biological Conservation, New York, v. 127, p. 247 - 260, 2006.

MINISTÉRIO DO MEIO AMBIENTE (MMA). Espécies Exóticas Invasoras: Situação Brasileira. Brasília: Ministério do Meio Ambiente e Secretaria de Biodiversidade e Florestas, 2006. 23 p.

OLDEN, J. D. Biotic homogenization: a new research agenda for conservation biogeography. Journal of Biogeography, v. 33, n. 12, p. 2027 - 2039, 2006.

OLDEN, J. D.; POFF, N. LeRoy; DOUGLAS, M. R.; DOUGLAS, M. E.; FAUSCH D. K. Ecological and evolutionary consequences of biotic homogenization. Trends in Ecology and Evolution, v. 19, n. 1, p. 18 - 24, 2004.

OLDEN, J. D.; POFF, N. L. Clarifying biotic homogenization. Trends in Ecology and Evolution. v. 19, n. 6, p. 283, 2004.

RICHARDSON, D. M. Commercial forestry and agroforestry as sources of invasive alien trees and shrubs. In: SANDLUND, O. T.; SCHEI, P. J.; VIKEN, A. Invasive species and biodiversity management. Dordrecht: Kluwer, 1999. p. 237 - 257.

RICHARDSON, D. M; HIGGINS S. I. Pines as invaders in the southern hemisphere. In: RICHARDSON D. M. Ecology and biogeography of Pinus. Cambridge: Cambridge University Press, 1998. p. 450 - 473.

ROSOT, M. A. D.; OLIVEIRA Y. M. M.; ALMEIDA A.; ZONTA, M. Implantação de reflorestamentos no estado do Paraná. Revista Madeira, Ourinhos, v. 83, p. 1 - 4, 2004.

SANCHES, J. H. Potencial invasor do chapéu-de-sol (Terminalia cattapa L.) em área de restinga. 83 f. Dissertação (Mestrado em Recursos Florestais) - Escola Superior de Agricultura “Luiz de Queiroz”, Piracicaba, 2009.

SOUZA, O. P.; MANCIN, C. A.; MELO, B. Cultura da goiabeira. <http://www.fruticultura. iciag.ufu.br/goiabao.html\#_Toc42258445>. Acesso em: 20/02/2009.

VIGILIATO, G. R.; ZAMPAR, R. Susceptibilidade das zonas de recuperação de uma unidade de conservação à invasão biológica por espécies arbóreas exóticas. Revista de Saúde e Biologia - SaBios, Campo Mourão, v. 6, n. 3, p. 25 - 37, 2011.

WELLS, M. J.; POYNTON, R. J.; BALSINHAS, A. A.; MUSIL, K. J.; JOFFE, H.; VAN HOEPPE, E.; ABBOTT, S. K. The history of introduction of invasive alien plants to southern Africa. In: MACDONALD, I. A. W.; KRUGER, F. J.; FERRARA, A. A. The ecology and management of biological invasions in southern Africa. Cape Town: Oxford University Press, 1986, p. 21 - 35.

WESTBROOKS, R. Invasive plants: changing the landscape of America: fact book. Washington: DC. Federal Interagency Committee for the Management of Noxious and Exotic Weeds, 1998. 107 p.

ZANCHETTA, D.; PINHEIRO, L. S. Análise biofísica dos processos envolvidos na invasão biológica de sementes de Pinus elliottii na estação ecológica de Itirapina, SP, e alternativas de manejo. Climatologia e Estudos da Paisagem, Rio Claro, v. 2, n. 1, p. 72 - 90, 2007.

ZILLER, S. R. A Estepe Gramíneo-Lenhosa no segundo planalto do Paraná: diagnóstico ambiental com enfoque a contaminação biológica. 268 f. Tese (Doutorado em Engenharia Florestal) - Universidade Federal do Paraná, Curitiba, 2000. 
